\title{
In vitro and ex vitro rooting of Spiraea betulifolia subsp. aemiliana (Rosaceae), an ornamental shrub
}

\author{
Dinara Muraseva ${ }^{1 *}$, and Vera Kostikova ${ }^{1}$ \\ ${ }^{1}$ Central Siberian Botanical Garden, Siberian Branch RAS, 630090 Novosibirsk, Russia
}

\begin{abstract}
Two methods of rhizogenesis - in vitro and ex vitro of Spiraea betulifolia subsp. aemiliana (C.K. Schneid.) H. Hara microshoots have been compared. Pulse treatment of microshoots with aqueous solutions of $4 \%$ "Heteroauxin" or $2 \%$ succinic acid (ex vitro rooting) did not effective rooting frequency ranged from 3 to $19 \%$. It was established that the in vitro rooting on nutrient media supplemented with auxins was a more effective technique, providing a high percentage of rooted microshoots. The use of half- strength MS medium supplemented with $0.1 \mu \mathrm{M}$ indolyl-3-butyric acid (rooting frequency $88 \%$, root number $3.5 \pm 0.3$ per plantlet) was found to be the most efective for in vitro rooting. The in vitro rooted regenerated plantlets were successfully acclimatized with $55 \%$ of survival rate.
\end{abstract}

\section{Introduction}

The genus Spiraea L. representatives are highly ornamental plant and have many garden forms and varieties, furthermore have diverse biological activity and various other beneficial properties $[1,2]$. Spiraea betulifolia subsp. aemiliana (C.K. Schneid.) H. Hara (syn. S. aemiliana C.K. Schneid.) is a part of the polymorphic plant complex of Spiraea genus (Rosaceae Juss.), Calospira C. Coch section. The subspecies is distributed only in the island part of Asian Russia (Sakhalin Island, Kuril Islands). Distinctive features of the subspecies are a shrub height up to $30 \mathrm{~cm}$, a compact crown, a dense white corymbose inflorescences, a small rounded lamina and an absence of the inflorescence follicles pubescence [3]. Besides Russia, S. betulifolia subsp. aemiliana also grows in Japan [4]. The taxon has a narrow range and can be recommended for inclusion in the Red Data Book of the Russian Federation or the regional Red Data Book of the Sakhalin Region. S. betulifolia subsp. aemiliana is a promising plant for landscape design in the European part of Russia and has decorative qualities [5]. Currently, propagation methods this taxon have not been developed.

The development of effective micropropagation protocols of ornamental plants allows scaling the process of producing plant material, while preserving all the ornamental characteristics of mother plants, the loss of which is possible during seed propagation.

*Correspondingauthor: dsmuraseva@,csbg.nsc.ru 
Moreover, the success of in vitro propagation depends not only on the optimization of the multiplication stage conditions, but also on the selection of the most effective methods of rooting and ex vitro acclimatization conditions. Rooting microshoots is carried out in several ways: 1) cultivation on nutrient media supplemented with auxins; 2) by pulsed treatment for several hours (2-24 hours) of microshoot bases with auxin solutions, followed by passaging on hormone-free nutrient media or planting microplants directly in a soil substrate; 3 ) treatment of shoot bases with auxin-containing powders, followed by planting in a soil substrate $[6,7]$. Techniques in which there is a cultivation stage on nutrient media are called in vitro rooting, where microplants, after treatment with auxins, are planted immediately in the soil - ex vitro rooting. Ex vitro rooting reduces the duration of cultivation due to the combination of the rooting stage and acclimatization. Moreover, acclimatization to ex vitro conditions is the final and often critical stage at any micropropagation protocol; in the case of death of regenerated plants at this stage, the efficiency of clonal micropropagation can significantly decrease $[6,8]$.

The aim of the study was to develop an effective method of rooting Spiraea betulifolia subsp. aemiliana microshoot.

\section{Material and methods}

Spiraea betulifolia subsp. aemiliana introduced at the experimental field of the Laboratory of phytochemistry of the Central Siberian Botanical Garden (Novosibirsk, Russia) was used. Intact plant material of Spiraea betulifolia subsp. aemiliana was collected at the site of its natural habitat in 2016 in the Kunashir Island (Kuril Islands, Russia).

The conglomerates of shoots obtained during clonal micropropagation were separated individually and used to optimize the stages of rooting and acclimatization to ex vitro conditions. Rhizogenesis induction was carried out in two ways. In the case of in vitro rooting, root formation was induced on Murashige-Skoog (MS) media [9] complete or with a half-strength content of macro- and microsalts, supplemented with indolyl-3-butyric acid (IBA) at a concentration of 0.1 and $1.0 \mu \mathrm{M}$. The passage duration at the in vitro rooting stage lasted 50-60 days. For ex vitro rooting, the shoot bases were pulse-treated with aqueous solutions of 4\% "Heteroauxin" (indolyl-3-acetic acid at concentrations $50 \mathrm{~g} / \mathrm{kg}$; Orton, Russia) for $3.5 \mathrm{~h}$ or $2 \%$ succinic acid (STK, Russia) for $16 \mathrm{~h}$, and then transferred immediately to a soil substrate for the rhizogenesis induction, thus combining the stages of rooting and acclimatization. Microshoots planted in a substrate without preliminary soaking in root formation stimulating solutions were a control. To acclimatize microshoots to ex vitro conditions, the soil mixture (Fasko +, Russia) supplemented with sand (3:1) was used as a substrate. Before planting, the substrate was preliminarily spilled with an aqueous solution of $\mathrm{KMnO}_{4}$. Microplants were planted in containers filled with the soil substrate and covered with a film to prevent desiccation. For 2 weeks after the beginning of acclimatization, a high humidity was maintained in the containers, gradually reducing it, then the film was completely removed. After 2.5 months plants were transplanted into individual pots $(0.41)$ and transferred to greenhouse conditions.

All cultures at the in vitro rooting stage were incubated at $23 \pm 2{ }^{\circ} \mathrm{C}$, under a light intensity of $54 \mu \mathrm{mol} \mathrm{m}-2 \mathrm{~s}-1$ under a $16-\mathrm{h}$ photoperiod. Acclimatization experiments were carried out at $23 \pm 2{ }^{\circ} \mathrm{C}$ under a 16-h photoperiod (room condition).

Data are presented as mean \pm standard error $(\mathrm{M} \pm \mathrm{SE})$. The signifcance level accepted was $P \leq 0.05$. The statistical analysis package Microsoft Excel was used to process the results.

\section{Results and discussion}


The rooting of in vitro raised microshoots is carried out on media supplemented with auxins: IBA, indolyl-3-acetic acid (IAA), or 1-naphthylacetic acid. Using IBA as the main inducer of rhizogenesis in the study is explained by numerous evidences of the effectiveness of this growth regulator for in vitro rooting various Rosaceae woody plants [10-12].

High rhizogenesis frequency (not less than $60 \%$ ) of shoots was obtained, the maximum frequency of in vitro rooting was $88 \%$ on $1 / 2 \mathrm{MS}+$ IBA $0.1 \mu \mathrm{M}$ medium. Cultivation on media supplemented with auxin stimulated the root formation, without callus formation on all nutrient media studied. It was established experimentally that the use of half-strength media led to the activation of root formation (Fig. 1), while an increase the IBA concentration to $1.0 \mu \mathrm{M}$ reduced the rhizogenesis frequency. The maximum root number and high rooting frequency was obtained on a $1 / 2 \mathrm{MS}$ supplemented with $0.1 \mu \mathrm{M}$ IBA, that allowed to consider the medium to be the best for in vitro rooting induction.

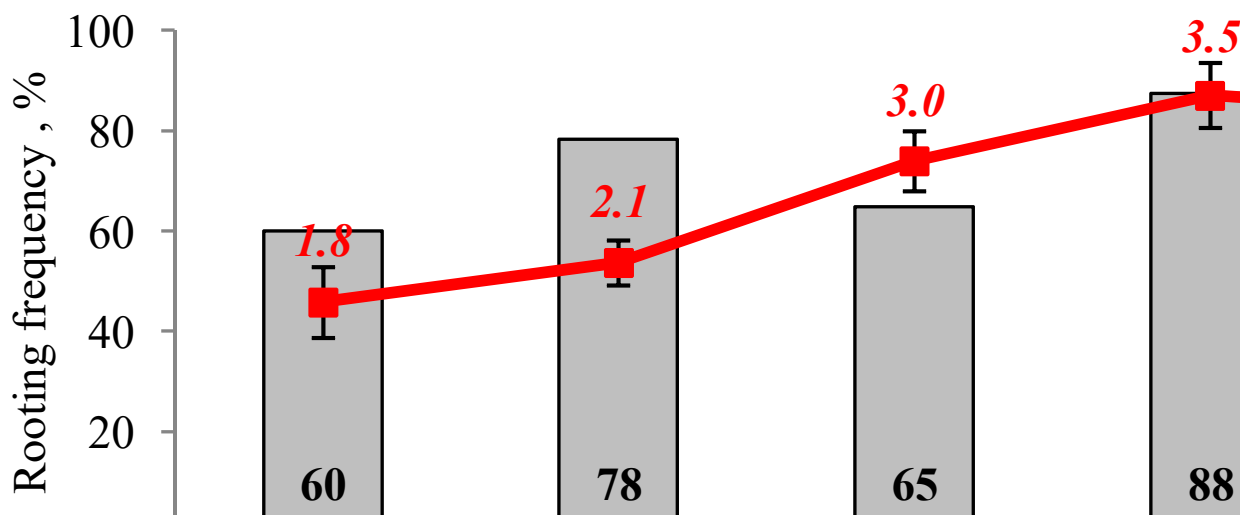

Fig. 1. In vitro rhizogenesis of Spiraea betulifolia subsp. aemiliana at the end of passage, MS and $1 / 2$ MS nutrient media, supplemented with 0.1 and $1.0 \mu \mathrm{M}$ IBA

Using "Heteroauxin" and succinic acid are well established itself in the rooting of green cuttings of ornamental shrubs, including spirea [13], while "Heteroauxin" is the trade name for IAA, which is widely used in in vitro rooting microshoots [14]. The effectiveness of using pulsed treatment with auxin solutions followed by subsequent transfer to soil substrates for various woody plants has been proven many times: for Acer L., Betula L., Malus P. Mill. [15], Balanites Delile, Citrus L., Syzygium P. Browne ex Gaertn. [16], Rhododendron L. [7]. The advantages of ex vitro rooting are the reduction of root damage during the transfer of microplants from the nutrient medium to the soil substrate, the normal anatomy of the roots with a high proportion of conductive tissue, and the higher resistance of microplants to stress, including water deficiency. In addition, the duration of cultivation is reduced due to the combination of the rooting and acclimatization stages [15].

Rhizogenesis induction of $S$. betulifolia subsp. aemiliana microshoots by pulsed treatment followed by planting in the substrate (ex vitro rooting) was found to be ineffective. A very low percentage of rooted plants were obtained: in the control group and at treatment with succinic acid, the death of microshoot was $97 \%$, using "Heteroauxin" was more effective $-19 \%$ of the rooted microshoot was obtained (Fig. 2). 


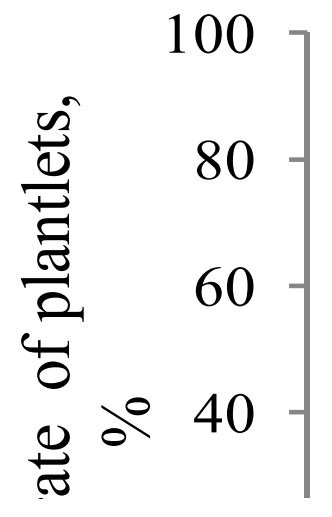

Fig. 2. Survival rate of Spiraea betulifolia subsp. aemiliana plantlets, rooted by in vitro and ex vitro methods

Such a low survival rate of plants indicated a weak development of the root system, which was formed as a result of pulse treatment. Previously M. T. McClelland et al. established experimentally that higher morphological parameters of root system growth were obtained by in vitro rooting, this tendency remains up to 20 weeks after transferring microplants to ex vitro conditions for Acer rubrum L. "Red Sunset" and Malus $\times$ domestica Borkh "McIntosh" [15]. In the present study, the acclimatization of in vitro rooted regenerated plants was almost threefold more effective and reached $55 \%$ of survival rate that indicates a better development of the root system in comparison with ex vitro rooting. Moreover, as noted by M. T. McClelland et al., in the early stages of development, roots formed in vitro or ex vitro vary significantly in anatomy; this is due to the availability of nutrients, water and oxygen in an in vitro culture, which leads to lack of need for the development of a secondary phloem and xylem. However, long-term growing in the soil substrate eliminates these differences and the anatomy of regenerated plant roots corresponds to that of intact plants [15]. In our study, the dynamics of growth and development of $S$. betulifolia subsp. aemiliana regenerated plants was leveled under the greenhouse conditions, all plants developed a voluminous root system and an above-ground part, which confirms the results obtained by M. T. McClelland et al.

Thus, an effective method providing a high percentage of rooting and acclimatization of $S$. betulifolia subsp. aemiliana regenerated plants was the in vitro induction of rhizogenesis on $1 / 2$ MS nutrient medium supplemented with $0.1 \mu \mathrm{M}$ IBA. The use of pulsed treatment of microshoots with solutions of $4 \%$ "Heteroauxin" (exposure $3.5 \mathrm{~h}$ ) or $2 \%$ succinic acid (exposure $16 \mathrm{~h}$ ) at ex vitro conditions was found to be ineffective for induction of root formation of the studied Spiraea subspecies. It is necessary to continue the study of the peculiarities of the rooting methods of $S$. betulifolia subsp. aemiliana microshoots to identify potential of root formation.

The work was supported by the Budgetary Project of the Central Siberian Botanical Garden, Siberian Branch of the Russian Academy of Sciences No AAAA-A17-117012610051-5.

\section{References}

1. Plant resources of the USSR: Flowering plants, its chemical contents, utilization. Families Hydraginaceae - Haloragaceae (Nauka, Leningrad,1987)

2. S. Sun, Y. Liu, X. Liu, S. Zhang, W. Wang, R. Wang, Y. Hou, W. Wang, Nat. Prod. Res., 33 (22), 3215-3222 (2019) 
3. V. Kostikova, V. Troshkina, BIO Web Conf. 16, 00014 (2019)

4. . Ohwi, Flora of Japan (DC: Smithsonian Institution, Washington, 1965)

5. V. Kryuchkova, V. Chernolikh, Success of modern science and education 2, 135-139 (2016)

6. D. Shornikov, S. Bryukhina, S. Muratova, M. Yankovskaya, R. Papikhin, Tambov University Reports. Series: Natural and Technical Sciences 15, 2 (2010)

7. Y. Zaytseva, E. Ambros, T. Novikova, Turczaninowia 21, 144-152 (2018)

8. O. Aladina, S. Akimova, I. Kovaleva, S. Dubrovskaja, E. Batrak, S. Aladin, Izvestiya TSKhA 3, 98-109 (2009)

9. T. Murashige, F. Skoog, Physiol. Plant. 15, 473-497 (1962)

10. B. Yıldırım, A. U. Turker, In vitro Cell. Dev. Biol. - Plant 45, 135-144 (2009)

11. A. Aygun, H. Dumanoglu, Front. Plant Sci. 6, 225 (2015)

12. V. Kirillov, M. Serafimovich, T. Stikhareva, B. Mukanov, Int. J. Agric. Biol. 21, 9971003 (2019)

13. T. Galdina, Modern science success 11, 16-18 (2016)

14. P. Skůpa, Z. Opatrný, J. Petrášek, Applied Plant Cell Biology, Plant Cell Monographs 22 (Springer-Verlag, Berlin, Heidelberg, 2014)

15. M. McClelland, M. Smith, Z. Carothers, Plant Cell Tiss. Organ. Cult. 23, 115-123 (1990)

16. J. Rathore, V. Rathore, N. Shekhawat, R. Singh, G. Liler, M. Phulwaria, H. Dagla, Plant Biotechnology and Molecular Markers (Springer, Dordrecht, 2004) 